DOE/ID/13682

DEVELOPMENT OF A DRILLROD/TELEMETRY RADAR

Raton Technology Research, Inc.

November 1999

Work Performed Under Contract No. DE-FG07-98ID13682

For

U.S. Department of Energy

Assistant Secretary for

Energy Efficiency and Renewable Energy

Washington, DC

By

Raton Technology Research, Inc.

Raton, New Mexico 
DOE/ID/13682

\section{DEVELOPMENT OF A DRILLROD/TELEMETRY RADAR}

Raton Technology Research, Inc.

November 1999

Work Performed Under Contract No. DE-FG07-98ID13682

Prepared for the

U.S. Department of Energy

Assistant Secretary for

Energy Efficiency and Renewable Energy

Washington, DC

Prepared by

Raton Technology Research, Inc.

Raton, New Mexico 


\section{Contents}

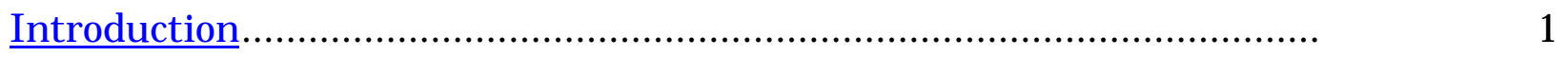

Description of the Radar Design Project..................................................

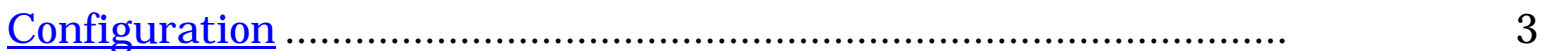

Radar Design Considerations..........................................................

Block Diagram of the Stepped-Frequency Radar .................................

Construction of the Radar Electronics ..................................................

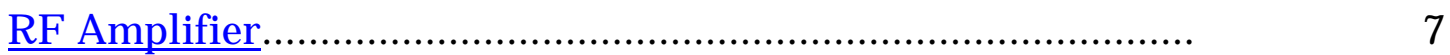

Phase Sensitive Detector .......................................................

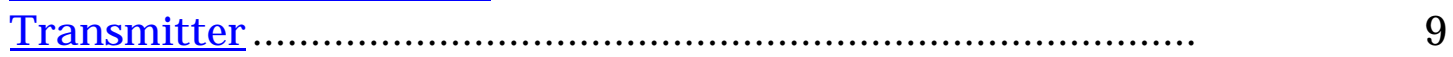

Synchronization Generator ……............................................. $\quad 10$

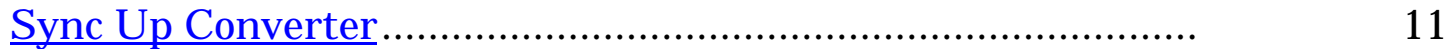

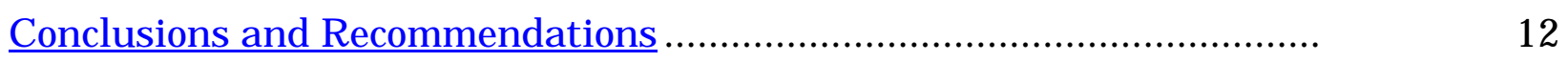




\section{Figures}

1. Application of borehole radar in fracture mapping ....................... 1

2. Cross section sketch of the radar enclosure................................... 3

3. Breadboard antenna array (bilobe transmitting pattern).............. 4

4. Measured magnitude and phase of the $\mathrm{CW}$ radar.......................... 5

5. Block diagram of the high frequency stepped frequency radar ..... 6

6. Block diagram of RF amplifier .................................................

7. Photograph of the phase-sensitive detector ................................... 8

8. Block diagram of the phase-sensitive detector .............................. 8

9. Transmitter printed circuit board ............................................. 9

10. Block diagram of the transmitter ...............................................

11. Photograph of the synchronization signal generator..................... 10

12. Block diagram of the synchronization signal generator.................

13. Block diagram of UP converter.................................................... 11

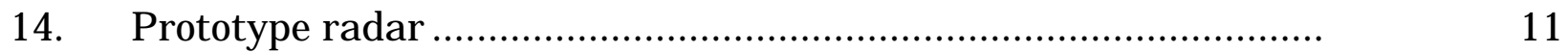




\section{Introduction}

Efficient extraction of deeply buried natural resources is dependent upon accurate geologic models. Geologists and geophysicists (geoscientists) develop models that describe the prevailing geologic structure by first performing mineralogical studies of cutting and core. Oftentimes, additional information is acquired by examining data from a suite of logging data. Field studies of formation outcrops add to the database. By constructing stratographic columns of acquired data, projections of strata between pairs of exploration wells is applied to define layering. Layering is assumed to be continuous or to become noncontinuous lenses in the geologic model. The model becomes the basis for developing plans for extraction of the resource. In recent years, surface and borehole seismic methods have been developed to validate these projections and search for geologic anomalies. The goal of these methods is to extend the depth of investigation from near wellbore to the entire geologic region between exploration wells.

Geoscientists working in geothermal and hydrocarbon recovery have a great deal in common with fellow geoscientists working in the mining industry. They appreciate the intractable problem of increasing the depth of investigation to tens of meters from the wellbore.

Figure 1 illustrates the factors controlling economic recovery from hydrocarbon reservoirs. Natural and man-made fractures surrounding the wellbore predominate the flow of fluids while fault and changes in structural geology may form barriers and traps. Mapping of fractures and identifying the fluid contained within them are essential to

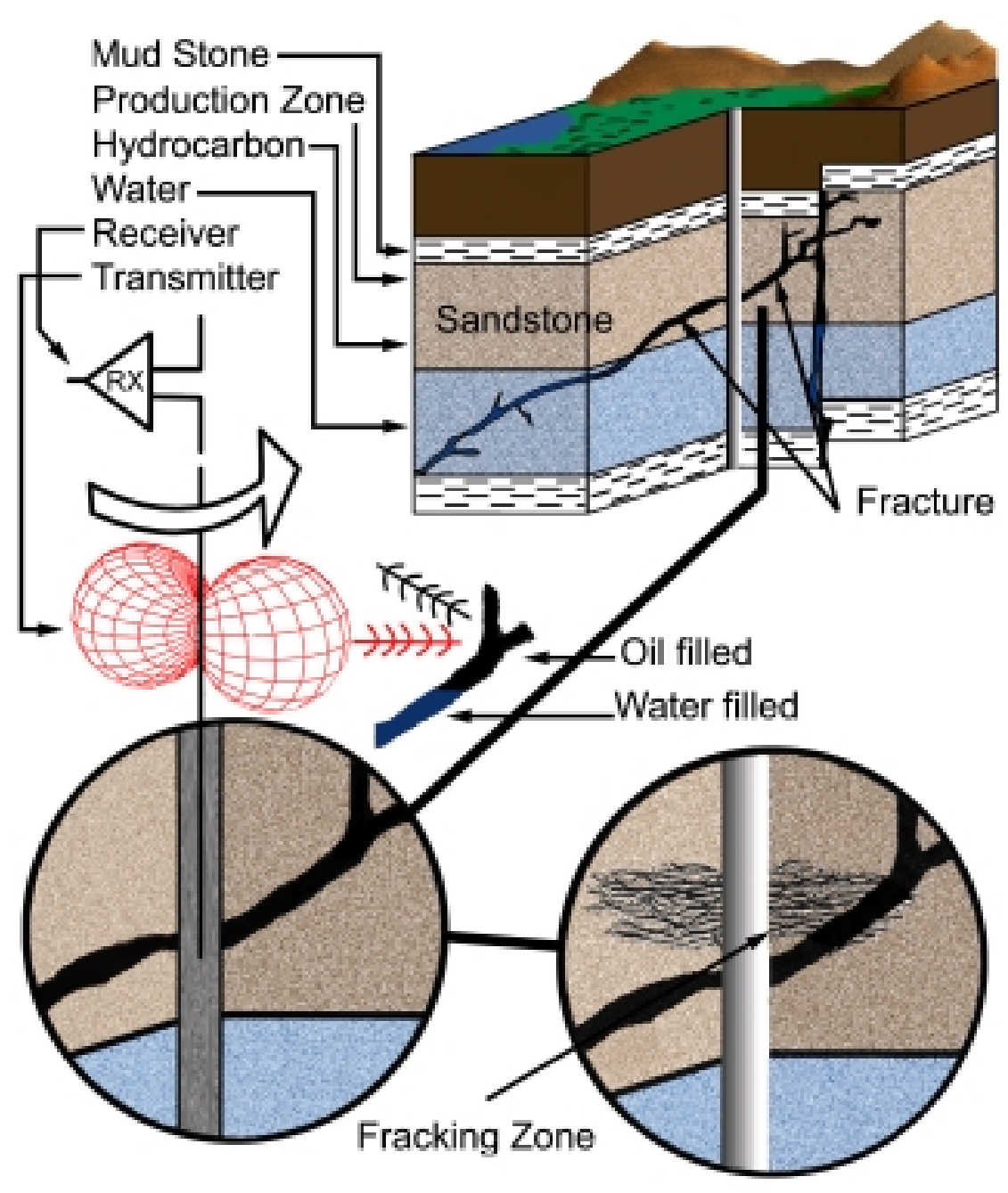

Figure 1. Application of borehole radar in fracture mapping 
smart fracking and sealing.

In the above illustration, above the water/brine saturation level, the fractures may be filled with hydrocarbon. Cementing in the water/brine saturated horizon will increase the oil-to-water ratio while fracking in the reservoir will increase hydrocarbon recovery. In geothermal wells, detection and imaging is required to optimize water injection and steam recovery.

The DOE's Mining Industry of the Future vision statement states that the industry will be faced with extraction from deeper and more difficult-to-mine resources. Undoubtedly, directional drilling and imaging while drilling (IWD) technology will be developed in future R\&D projects.

Members of the Society of Exploration Geophysicists (SEG) focus most of their work on the physics principles of seismic wave propagation where wave velocity is the observable in detecting changes in density, stress, and structure in the geologic target. Electromagnetic wave propagation can be complementary to seismic wave methods because the electrical parameters of the geologic target can yield information on porosity and the type of fluids in the rock mass. The reflection, diffraction, and absorption information can also be used to image faults and measure distance to boundary layers in the geologic target.

The goal of this project was to develop a borehole radar tool that would acquire data within tens of meters from the wellbore. For geothermal and hydrocarbon applications, the tool was to be developed to acquire data for mapping fractures surrounding the wellbore. In mining of coal, the radar would acquire data for determining coal seam thickness and detect geologic anomalies ahead of mining.

\section{Description of the Radar Design Project}

A radar that must be integrated into a drillstring presents a number of difficult-to-solve problems to the design team. While it is a simpler problem to design a radar tool for logging in recently completed wells, stress in the target region may contribute to hole closure; thus, the radar must be designed to operate within the drillrod where electric power and data communication must be specially designed for the drillrod environment. The potential for hole closure is one of the compelling reasons to collect radar data while drilling. Because of the high cost of drilling, these holes are oftentimes lined soon after completion. Metallic pipes limit the application of electromagnetic wave methods. Another is that directional drilling requires information that can be used in the control of the down-the-hole motor gimbal assembly. When drilling in a coal seam or a sandstone hydrocarbon layer, the well bore must be maintained with respect to one of the boundary layers. 


\section{Configuration}

The radar was designed to be integrated into a drillstring sub with an outside diameter of $3 \frac{1}{2}$ inches $(89 \mathrm{~mm})$. The radar electronics enclosure must be designed to be inserted into the annulus of the drillrod. Centralizers caused the enclosure center line to coincide with the center line of the drillrod.

The mechanical design of the borehole radar features a 13/4-inch $(45 \mathrm{~mm})$ outside diameter stainless steel tube. A cross section of the enclosure design is shown below (Figure 2).

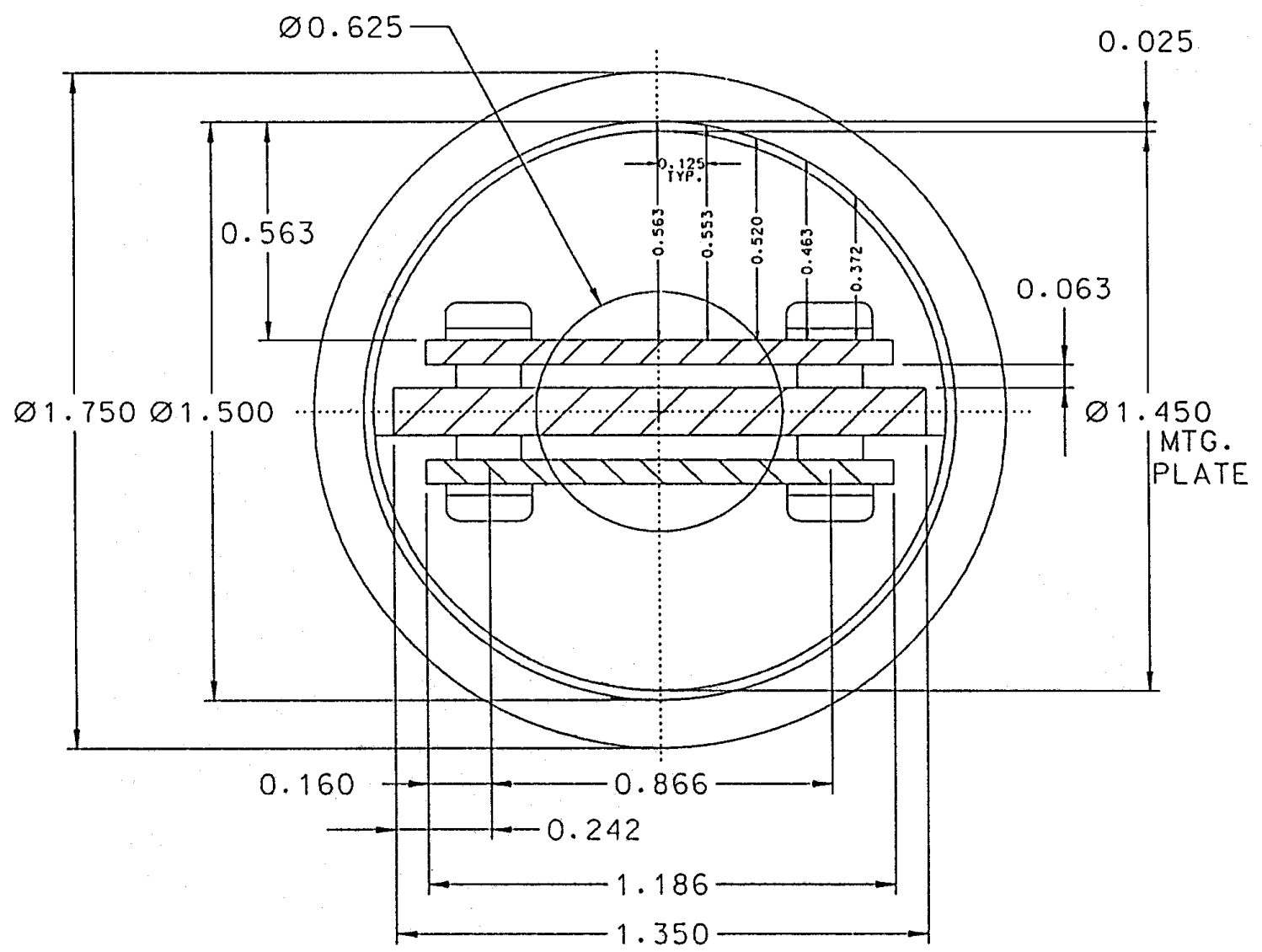

Figure 2. Cross section sketch of the radar enclosure

\section{Radar Design Considerations}

This project focused on the development of a state-of-the-art borehole tool that operates above the induction logging tool frequency (above $300 \mathrm{kHz}$ ) and below frequencies normally used in radar $(20 \mathrm{MHz})$. In the "niche" frequency band from $300 \mathrm{kHz}$ to $20 \mathrm{MHz}$, the attenuation rate $(\alpha)$ and phase constant $(\beta)$ are mathematically represented by 


$$
\alpha=\beta=\sqrt{\frac{\mu \sigma \omega}{2}} ; \frac{\sigma}{\omega \varepsilon}>1
$$

where $\mathrm{T}=2 \mathrm{Bf}$ and $\mathrm{f}$ is the frequency in Hertz

$:=:_{0}: 0$ is the magnetic permeability and the free space permeability $:_{0}=4 \times 10^{-7}$ henries per meter

$\Phi=$ is the conductivity in Siemens per meter of the geology

, = ,r,o is the permittivity and $\mathrm{G}_{0}=1 / 36 \mathrm{~B} \times 10^{-10}$ forads per meter.

The term $\frac{\sigma}{\omega \varepsilon}>1$ indicates that conduction currents predominate in the natural media.

In the subsurface radar problem, we infer from Maxwell's equations that

$$
\nabla x \overline{\mathrm{H}}=\sigma \overline{\mathrm{E}}+\mathrm{i} \omega \varepsilon \overline{\mathrm{E}}-\frac{\mathrm{dP}}{\mathrm{dT}}
$$

It is the electric field (E) that governs the flow of current in the target. The first term on the right side of Equation 2 defines the conduction current vector in a fracture filled with high conductivity $(\Phi)$ fluids. The second term is the displacement current that flows in a low conductivity fluid and the right-hand term accounts for the natural polarization occurring in low conductivity fractures.

Using a breadboard antenna array illustrated in Figure 3, a continuous wave (CW) primary field is used to illuminate the geologic target.

The electric dipole antenna is located in the null electric field of the transmitter horizontal magnetic dipole fields. The magnetic dipole fields in the broadside $\left(2=90^{\circ}\right)$ angle exhibit vertically polarized primary electric field(s). For vertically diposed fractures filled with conductive fluid, conduction current flow causes a secondary electric field to return to the receiving antenna.

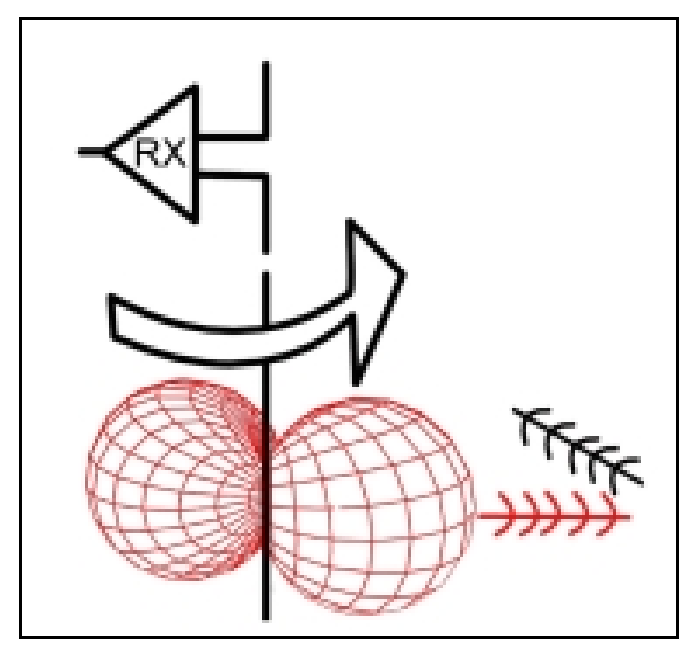

Figure 3. Breadboard antenna array (bilobe transmitting pattern) 
With an operating frequency of $1 \mathrm{MHz}$, a high conductivity fluid (metal pipe) and a low conductivity fluid (plastic pipe) were detected at 6 and 20 meters, respectively. The measured data is shown in Figure 4.

Because the geology surrounding the wellbore is dispersive when considering electromagnetic wave propagation, a stepped-frequency radar design was selected over a short pulse radar design approach. In dispersive media, the velocity of each frequency component of short pulse spectrum is not constant. Another problem relates to the ring downtime period of the transmit antenna. The companion receiver in a pulse radar must be turned off during the ring downtime period. This phenomena establishes the minimum useful depth of

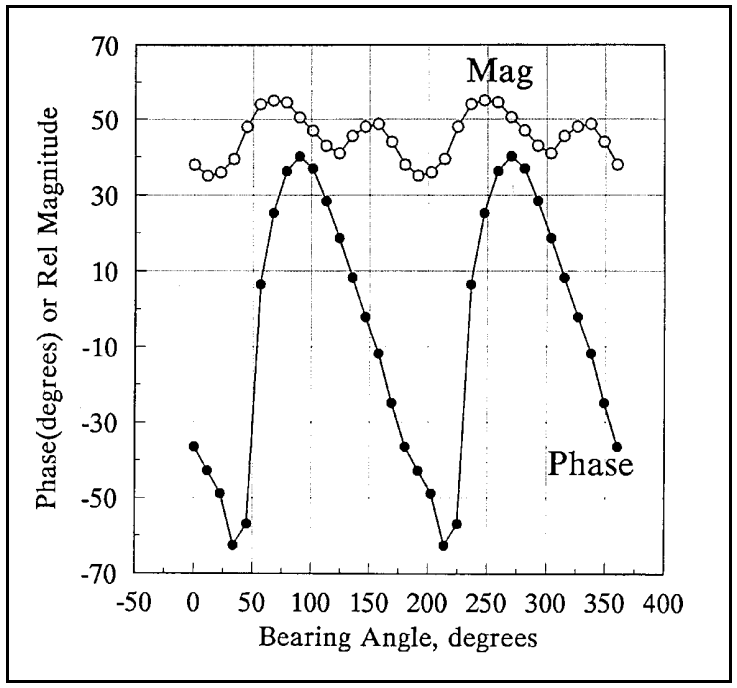

Figure 4. Measured magnitude and phase of the CW radar investigation for the pulse radar because the radar signal is attenuated in propagating on the round trip path to the target. The upper range limit is limited by the detection sensitivity of the radar. Pulse radar are disadvantaged by their wideband receiver requirements. To describe the widebandwidth problem, the threshold receiver sensitivity is given by

$$
\mathrm{S}_{\mathrm{T}}^{10}=-168+10 \lg _{10} \mathrm{BW}+10 \lg _{10} \mathrm{NF} \mathrm{dB}
$$

where BW is the noise bandwidth of the receiver

$\mathrm{NF}$ is the total noise figure

$\mathrm{S}_{\mathrm{T}}^{10} \quad$ is the signal that produces a $10-\mathrm{dB}$ signal-to-noise ratio in the IF.

If the occupied bandwidth of the pulsed radar is $10 \mathrm{MHz}$, then the receiver threshold sensitivity is decreased by $70 \mathrm{~dB}$ over a radar with a $1-\mathrm{Hz}$ noise bandwidth. To achieve the $1-\mathrm{Hz}$ noise bandwidth, a wider instantaneous bandwidth can be designed into a synchronous receiver circuit, then sampling at a higher rate and averaging can be used to realize a $1-\mathrm{Hz}$ design objective. Since a phase-coherent design can be implemented in a radar frequency transposition circuits, synchronous detection can be realized in a practical design. Synchronous detection is an optimum method for detecting sinusoidal signals embedded in electrical noise. It is optimum in the sense that the receiver threshold sensitivity is maximized. Another advantage of synchronous detection is that the phase of the radar return signal can be measured along with the signal amplitude. The price paid for stepped-frequency 
radar is the time period required to measure the ensemble of frequency components (steps) in the radar spectrum. The frequency spectrum is then processed in the Fourier transform algorithm to determine the time domain response of a geologic anomaly in the target area. The phase response can be used to determine the type of pore space fluid in the target area. In the logging while drilling (LWD) application of stepped-frequency radar, the forward travel velocity of the drill is slow. This enables the use of stepped-frequency radar.

\section{Block Diagram of the Stepped-Frequency Radar}

The block diagram of the radar is illustrated in Figure 5.

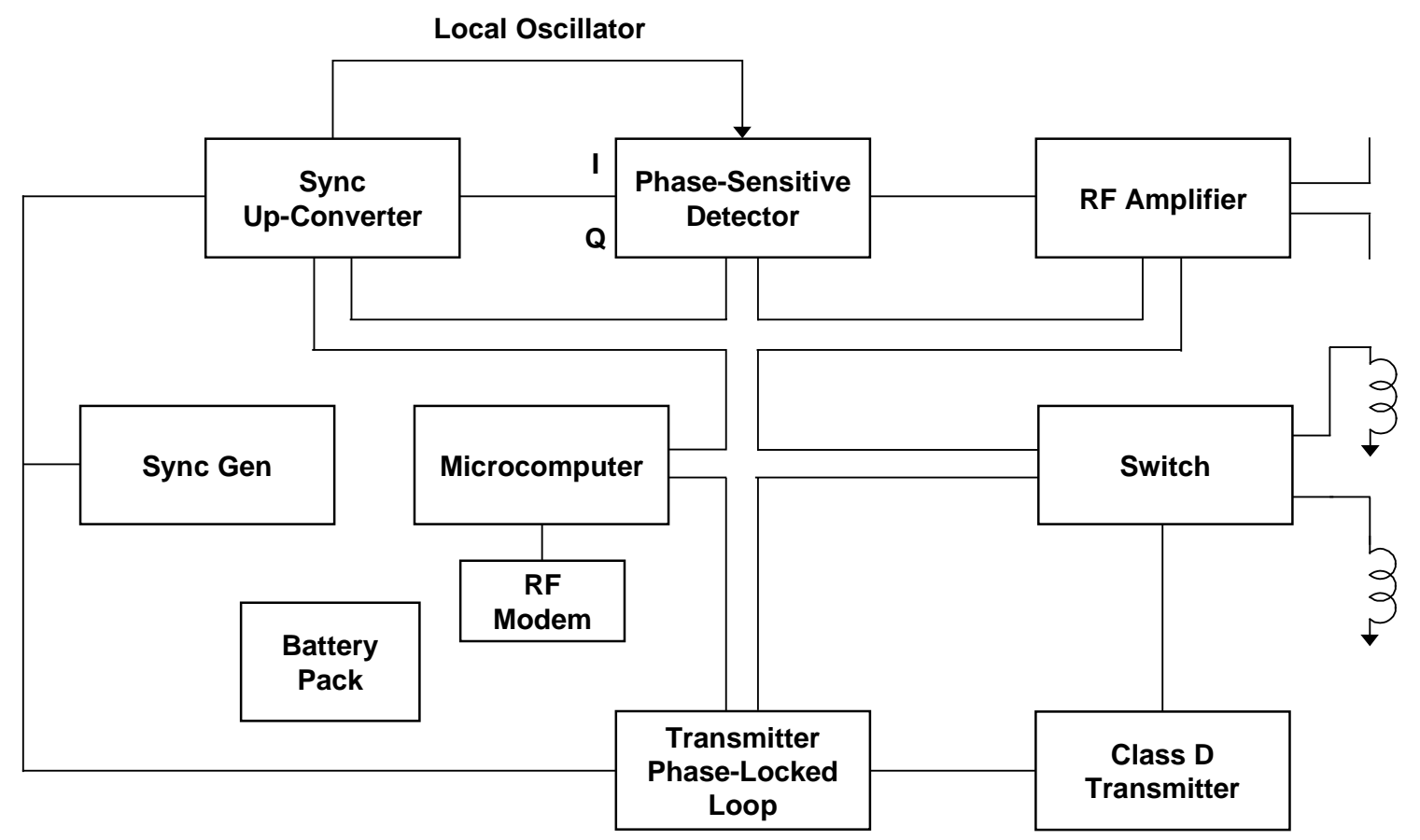

Figure 5. Block diagram of the high frequency stepped frequency radar

The coherent frequencies used in the stepped-frequency radar design are derived from a crystal oscillator in the sync generator (sync gen). The frequency source in the transmitter includes a phase-locked loop (PLL). The RF amplifier and phase-sensitive detector features a PLL with an operating frequency that is offset in frequency from the transmitter PLL by the receiver intermediate frequency (IP). The IF frequency selected for this particular radar design is $10.7 \mathrm{MHz}$. The in-phase (I) and quadrature (Q) radar return signals are measured with the synchronous detector. These signals are converted into digital signals by the analog-to-digital (A/D) circuit. The I and $\mathrm{Q}$ digital signals are sent to the microcomputer. An algorithm in the microcomputer determines the amplitude and phase of the radar return signal. 
The measured data is applied to a radio frequency modem. The modem operates in the induction mode causing a current to flow along the drillstem to a companion receiver at the drill collar.

The initial design of the borehole radar antenna array was based upon a quadrature alignment of horizontal magnetic dipole transmitting antennas. The receiver antenna was designed as a sleeve electric dipole. The electric dipole is physically located in the null of the transmitting antenna array pattern. The radar was designed to operate in the 1 to $20-\mathrm{MHz}$ frequency range. The lower end of this frequency range is above the upper frequency of conventional resistivity logging tools and the upper frequency of this range is below that of radar, such as designed for nuclear waste repository studies by the International Atomic Agency. The operating frequency range enables the depth of investigation to extend tens of meters into the surrounding rock mass. Preliminary tests of the radar array determined that the minimum transmitting and receiving antenna separation distance of 2 meters was required to suppress the crosstalk below the target return level.

\section{Construction of the Radar Electronics}

\section{RF Amplifier}

The block diagram of the RF amplifier is illustrated in Figure 6.

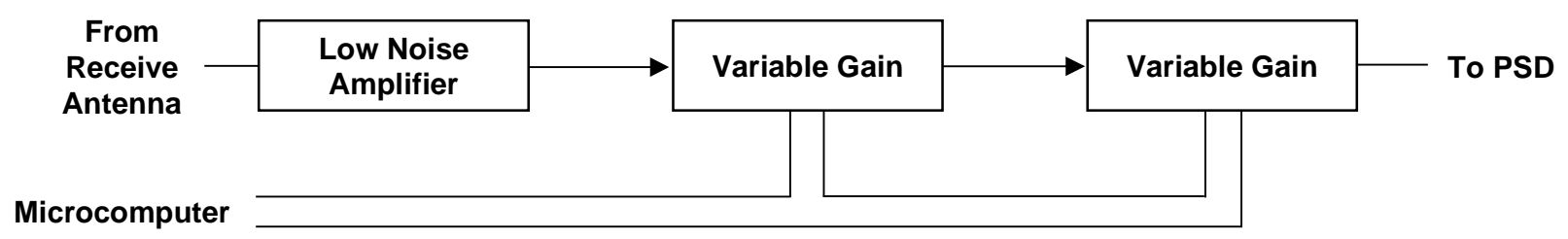

Figure 6. Block diagram of RF amplifier

The RF amplifier has a high threshold sensitivity ( 0.9 nanovolt per square root hertz). The RF amplifier includes two sections of gain controlled amplifiers. The gain is automatically set by the microcomputer. 


\section{Phase Sensitive Detector}

The photograph of the phase sensitive detector is shown below (Figure 7).

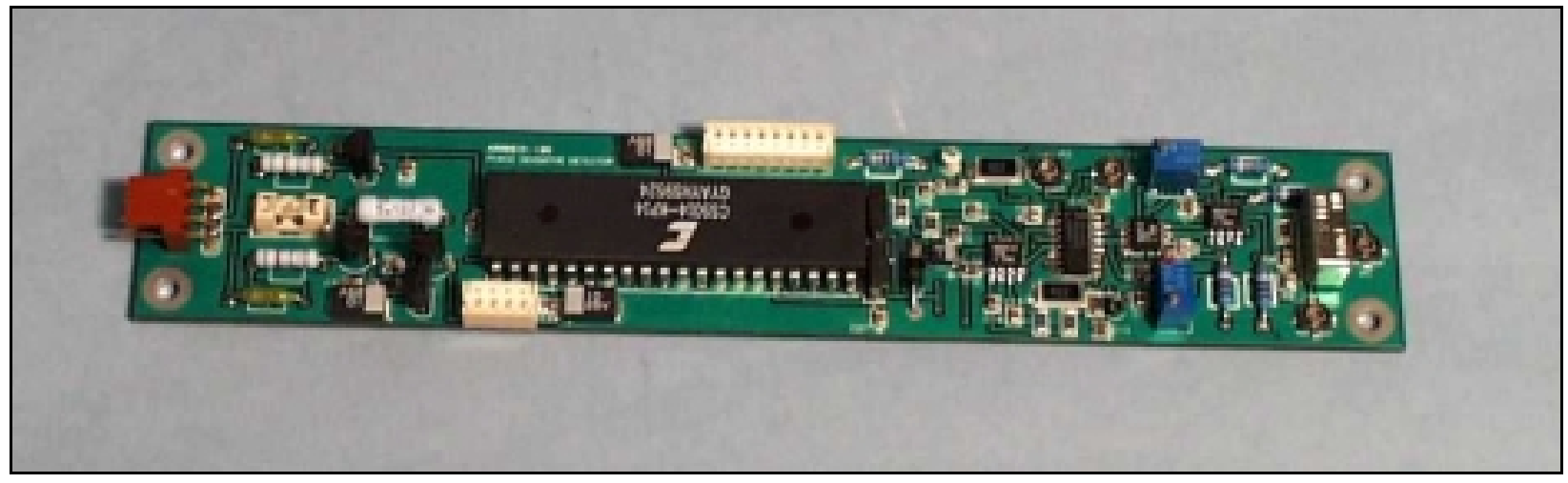

Figure 7. Photograph of the phase-sensitive detector

The block diagram of the phase sensitive detector is shown in Figure 8.

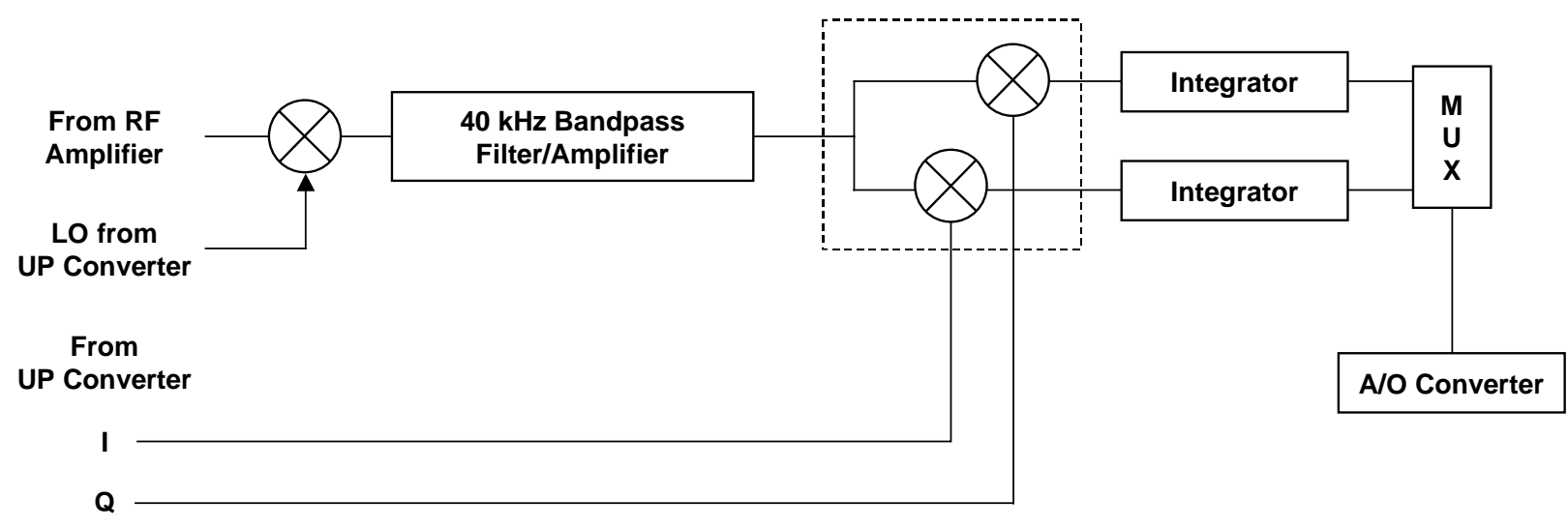

Figure 8. Block diagram of the phase-sensitive detector

The phase sensitivity detector (PSD) has a first stage that is a mixer followed by a $40 \mathrm{kHz}$ filter. The first mixer is used to translate the radar return signal to the $40 \mathrm{kHz}$ intermediate frequency (IF). The phase-sensitive detector is an in-phase (I) and quadrature $(\mathrm{Q})$ analog switch followed by a 14-bit analog-to-digital converter. The microcomputer reads the I and Q values of the radar signal. 


\section{Transmitter}

The photograph of the transmitter printed circuit board is shown below (Figure 9).

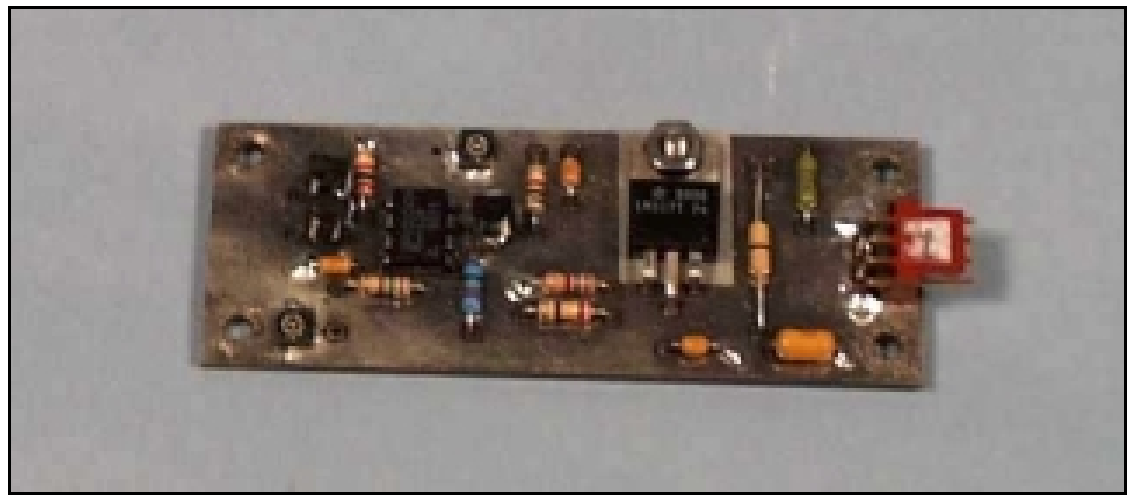

Figure 9. Transmitter printed circuit board

The block diagram of the transmitter is shown below (Figure 10).

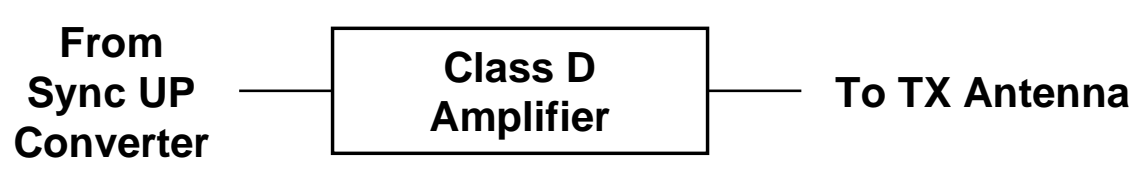

Figure 10. Block diagram of the transmitter

The transmitter is a Class D amplifier that generates a sinusoidal signal. The signal is sequentially switched to the horizontal magnetic dipoles oriented at $90^{\circ}$ with respect to each other. The magnetic moment produced by the transmitter is 1 ampere turn square meter. 


\section{Synchronization Generator}

The photograph of the synchronization board is shown below (Figure 11).

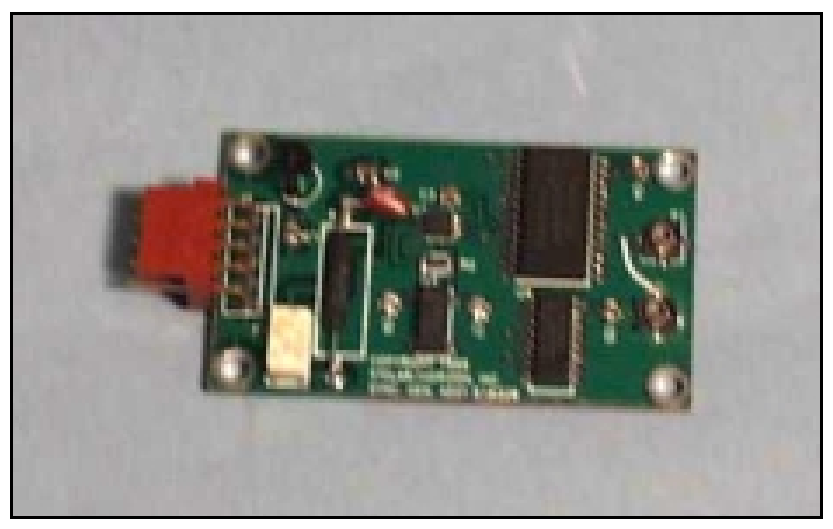

Figure 11. Photograph of the synchronization signal generator

The block diagram of the synchronization signal generator is shown in Figure 12 below.

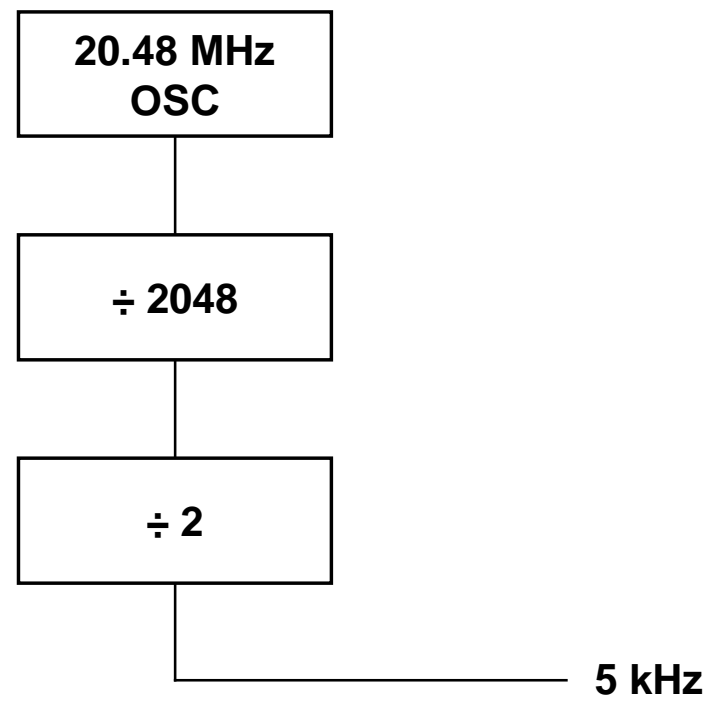

Figure 12. Block diagram of the synchronization signal generator 


\section{Sync Up Converter}

Table of Divider Values

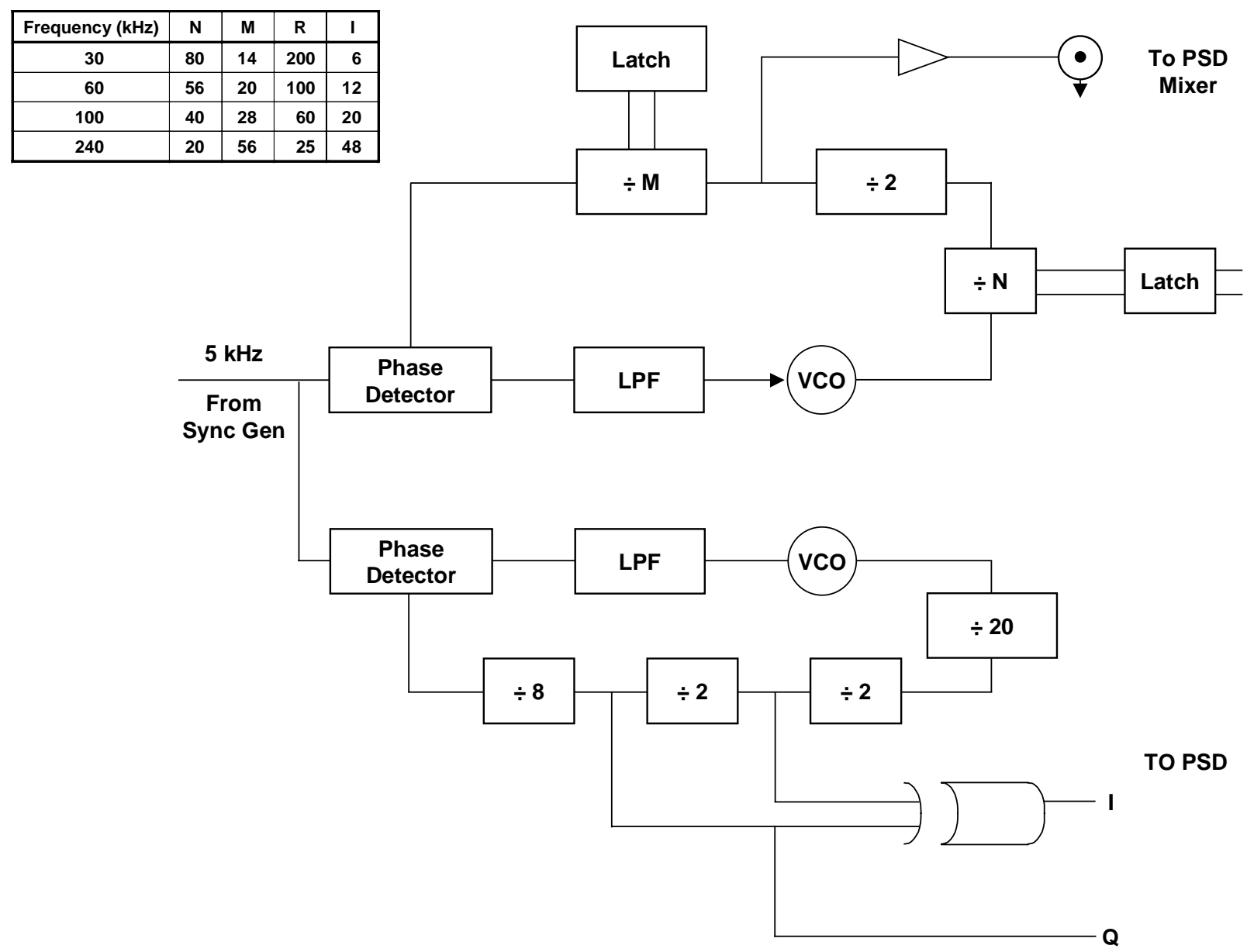

Figure 13. Block diagram of UP converter

The prototype radar is shown in Figure 14.

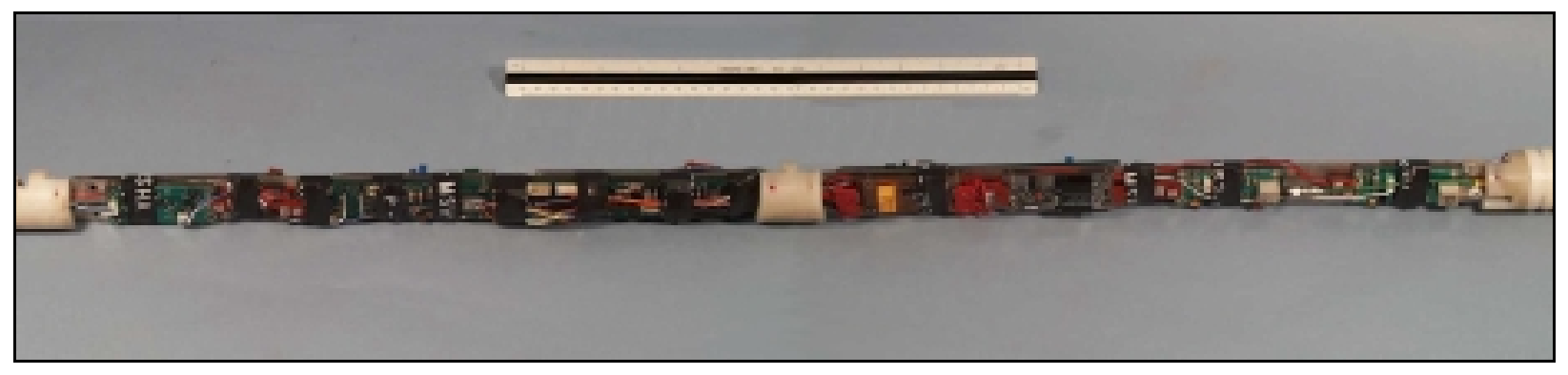

Figure 14. Prototype radar 


\section{Conclusions and Recommendations}

This project provided an opportunity to advance the state of the art in borehole radar technology. Among the accomplishments of this work area were the design and building of a set of printed circuit modules enabling the building of a phasecoherent stepped-frequency radar. These modules featured surface-mount components, which significantly reduced physical size of the modules. This project paves the way for radar technology needed in the DOE's Mining Industry of the Future program. By integrating the radar enclosure into the drill sub, the radar will become an enabling sensor for navigation of directional drills. In the original 16 to 1 Gold Mine near Nevada City, California, the radar will enable drilling instead of tunneling to locate specimen gold to be extracted from the massive quartz seam. This particular mine has miles of development drifts in which specimenquality gold remained hidden by the white quartz of the rib, back, and floor. Standard metal detectors were employed to recover millions of dollars in specimen gold within 12 inches of the exposed surface of the drifts. During the formation of this gold deposit, specimen gold was injected into the fractures of the recently cooled solid white quartz forming bright gold "trees." These gold specimens are especially wonderful to behold, resulting in a "gold fever" experience! The radar, along with drilling, will enable this mine to return to production from its idle status. In coal mining, the radar will enable the measurement of seam thickness from horizontal exploration wells. The radar is urgently needed in the coal fields of West Virginia, Virginia, and Kentucky where high-quality, low-sulfur coal reserves remain in thin seams. Extraction from these seams is impacted by paleochannels that can scour the seam, reducing the seam height. Knowing the location of scours along with scan height well in advance of mining will return these mines from an idle to a production status. Miners and their families idled in the Appalachian region fall into poverty. Radar will return this work force to productivity.

The technology developed in this project is only a step of development away from enormous benefit to the coal mining industry-especially in the Eastern coal fields where chronic underemployment exists along with low sulfur and ash coal reserves. This next step would be to integrate the radar electronics into a drill sub and evaluate its performance in field trials. 